\title{
Investigating the Effect of Education on Self-Care among Chronic Heart Failure Patients Admitted to Shahid Mostafa Khomeini Hospital of Ilam
}

\author{
Samira miss Qavam ${ }^{1}$, Ali Sahebi ${ }^{2}$, Masoumeh Shohani ${ }^{2}$, Firoz Balavandi ${ }^{1}$, Ramak Qavam ${ }^{3} \&$ Hamed Tavan $^{2}$ \\ ${ }^{1}$ Dept of Cardiology, Hospital of Shahid Mostafa Khomeini, Ilam University of Medical Sciences, Ilam, Iran \\ ${ }^{2}$ Nurse, Faculty of Nursing and Midwifery, Ilam University of Medical sciences, Iran \\ ${ }^{3}$ Colorectal Research Center, Rasoul-e-Akram Hospital, Iran University of Medical Sciences, Tehran, Iran \\ Correspondence: Hamed Tavan, Ilam University of Medical Sciences, Faculty of Nursing and Midwifery, PO Box: \\ 69391-77143, Ilam, Iran. Tel: 98-841-222-7123; Fax: 98-841-222-7134. E-mail: hamedtavan@gmail.com
}

Received: June 27, 2016 Accepted: September 5, 2016 Online Published: October 18, 2016

doi:10.5539/gjhs.v9n5p79 URL: http://dx.doi.org/10.5539/gjhs.v9n5p79

\begin{abstract}
Background: Congestive heart failure is a common cause of hospitalization. If patients can adhere to self-care behaviors, the progression of the disease can be prevented. The aim of this study is to evaluate the effect of education on self-care in chronic heart failure patients admitted to Shahid Mostafa Khomeini Hospital of Ilam in 2016.

Methods: This study is of intervention typeand 40 patient's sufferingfrom heart failure were selected. Research tools include a standard indicator questionnaire for measuring self-care by patients. The questionnaire contains 22 questions about their certainty ofself-care. Four point Likert scale was used for scoring and SPSS V.19 was used for data analysis.
\end{abstract}

Results: The sample consisted of 16 men (40\%) and 24 women (60\%) most of which were married (75\%). The statistical correlation between the total score of self-care behavior before and after education was significant ( $\mathrm{P}$ VALUE $=0.003$ ), which shows that the education conducted on the patients was effective and caused more scores in all areas.

Conclusion: Self-care behavior can be attained and spread through education. It is recommended that the patients suffering are given enough information about their diet and activities after their discharge from hospital.

Keywords: self-care, patient education, heart failure, hospital

\section{Introduction}

Heart failure is the most common reason for hospitalization of individuals over 65 years and the second most common reason for visiting a doctor's office. Patients suffering heart failure are frequently hospitalized due to the worsening of their symptoms (Alizadeh, Ashktorab, Nikravan Mofrad, \& Zayeri, 2014).

Similarly, in Iran, heart failure is a major cause of disability and death, and with a change in the population age pyramid and aging of young people in Iran today, it will increase in the near future beyond the current number, that is, 3,500 patients per one hundred thousand people. According to the statistics of the Center for Disease Control in Iran, the prevalence of heart failure in patients in 18 provinces was reported at 3337 in 100,000 people (Bagheri, Yaghmaei, Ashktorab, \& Zayeri, 2015). Adherence to self-care behaviors in patients suffering chronic diseases is of great importance and patients can enhance their comfort, performance capabilities and processes of recuperation on learning self-care skills. Due to the consequences of disease and treatment, patients suffering chronic heart failurehave to face with changes in self-care needs and to deal with problems only through self-care. In recent years, focus on supportive care and education of patients suffering heart failure has been increasingly taken into consideration and the focus of treatment is mostly directed to adherence to treatment and self-care (Gonzalez, Luopn, Urrutia, Altimir, \& Coll, 2005; Moraveji, Yaghmaei, \& Bagheri,2015).

Several studies have also shown that patients with heart failure suffer from a poor physical functioning and depression and lower quality of life compared to patients with other chronic diseases such as chronic obstructive 
pulmonary disease, arthritis, unstable angina, and patients with a history of myocardial infarction. In comparison with other chronic diseases, this disease causes more destruction to individual'sfunction in social, family, and marital relationships and reduces professional performance (Johansson, 2006; Chattoo \& Atkin, 2009).

Nurses play an important role in health promotion and education of self-care behaviors. By identifying these behaviors and thefactors facilitating these behaviors, they can plan interventions to promote self-care behaviors and thereby to improve the quality of life in these patients. Self-care is a complex behavior that is controlled by a combination of biological- behavioral factors. Social support is known as a psycho-social factor and a facilitator of health behavior (Sandra, 2008; Morovati \& Rouhani Tonekaboni, 2009).

Since life expectancy can provide good motivation for self-care in patients and, on the other hand, it can be effective in controlling the risk factors leading to relapse in patients with heart failure, the aim of the present study is to evaluate the effect of education on self-care in chronic heart failure patients admitted to Shahid Mostafa Khomeini Hospital of Ilam in 2016.

\section{Materials and Methods}

The present study is an interventional study conducted on the patients admitted to Shahid Mostafa Khomeini Hospital of Ilam over a period of one month from late April to late May of 2016. In this study, the sample size was based on the number of patients admitted to the CCU where 40 patients were selected. The study population consisted of patients diagnosed with heart failure confirmed by a specialist, echocardiographic evidence of cardiac dysfunction recorded in the report, an ejection fraction equal to and lower than $25 \%$, heart failure class III, II, I according to New york Heart Association classification. The patients were 45 years and older enjoyingthe least literacy who wereadmitted to medical education center of Shahid Mostafa Khomeini Hospital of Ilam to follow up their treatment as an inpatient or outpatient. The total number of samples was 50. The patients with a medical history of neurological problems (cerebrovascular accidents, transient ischemic attack, short-term memory impairment or dementia), lack of mental stability (according to medical records), inability to speak Farsi, auditory and visual disorders, as well as the patients with a history of working in hospitals or receiving information about self-care on heart failure were excluded from the study. This study was approved by the Ethics Committee on Research and Technology Deputy of Guilan University of Medical Sciences. Informed consent in writing was obtained at the beginning of the study from each of the participants in the study. The participants were assured that they are able to freely leave the study at every step. Furthermore, they were ensuredon the confidentiality of patient information. After training the patientsonself-care by the researcher using visual aids (pamphlets, video projectors), the same questionnaire was completed by the patients one month later.

Data collection tool consisted of four parts: the first part included demographic data (gender, age, marital status, educational level, underlying disease, and duration of the disease). The second part included a standard self-care indicator questionnaire for measuring self-care by patients suffering from heart failure, which contained three areas: the first area consisted of 10 questions about maintenance of self-care. The second area consisted of six questions about management of self-care. The third area consisted of six questions about the reliability of self-care.

Content validity was used to confirm the validity of the questionnaire to the effect that the questionnaire was handed over to 10 self-care behavior experts whosecomments were applied and received final confirmation. Reliability of the questionnaire was also determined through a test-retest method based on a pilot study using 10 patients. Cronbach's alpha coefficient was 0.78

Likert scale (never $=1$, sometimes $=2$, often=3, always $=4$ ) was used for scoring self-care area and, in total, the scoresrangedbetween 10-40 in this area. The second area ranged between 6-28 scores. The third area ranged between 6 and 24 scores. In total, the score of the whole questionnaire ranged between 22-92, which was ultimately divided into 4 categories: low self-care (between 22-39 scores), moderate to low self-care (between 39-57 scores),moderate to high self-care (between 57-74 scores), and high self-care (between 74, 92 scores). The scores before and after training were also compared and discussed.

All data were collected by the researcher through interviews with patients and reviewing their medical records. After coding, the collected data were entered into SPSS V.19 and analyzed. Descriptive statistics (frequency, mean, standard deviation) and inferential statistics (independent t-test and one way ANOVAwas used to determine the relationship of self-care behavior before and after training with demographic characteristics. Level of significance for the tests was considered at $(\mathrm{P}<0.05)$.

\section{Results}

The samples included 16 men (40\%) and 24 women (60\%) most of which were married (75\%).Other demographic data are given in Table 1. In Table 2, the average score of self-care by patients with heart failure before and after the 
training is given, whichsuggests that the average scorehas increased in all areas. Table 3 shows the classification of scores obtained for self-care by patients with heart failure before and after the training. The correlation between the total score of self-care behavior before and after training was significant (P VALUE $=0.003$ ). This indicates that the training conducted on the patients was effective and caused more scores in all areas.

Table 4 compares self-care behavior scores before and after training based on demographic variables and shows that, generally, the average score for women was higher than that for men. However, the unmarried group obtained higher scores before training but the score of the married group increased after the training. Given the occupation, the average score of self-care behavior forunemployed subjects was higher than that of self-employed ones. The rest of the data is given in Table 4 in more detail.

Table 1. Demographic information of the study sample

\begin{tabular}{lll}
\hline Demographic variables & Sub-Categories & Number (\%) \\
\hline Age & 18-39.9 years & $8(20 \%)$ \\
& $40-59.9$ years and over & $24(60 \%)$ \\
\multirow{3}{*}{ Gender } & 60 years and over & $8(20 \%)$ \\
& Male & $16(40 \%)$ \\
Marital status & Female & $24(60 \%)$ \\
& Unmarried & $10(25 \%)$ \\
Occupational status & Married & $30(75 \%)$ \\
& Unemployed & $20(50 \%)$ \\
Education & Self-employed & $20(50 \%)$ \\
& Illiterate & $16(40 \%)$ \\
& Middle School Diploma & $16(40 \%)$ \\
& High school diploma & $8(20 \%)$ \\
\hline
\end{tabular}

Table 2. Average scores of self-care by patients with heart failure before and after training

\begin{tabular}{lllllll}
\hline & Areas & $\begin{array}{l}\text { Average } \\
\text { score }\end{array}$ & $\begin{array}{l}\text { area } \\
\text { score }\end{array}$ & $\begin{array}{l}\text { Highest } \\
\text { scorest }\end{array}$ & $\begin{array}{l}\text { Standard } \\
\text { deviation }\end{array}$ & $\begin{array}{l}\text { Test (t-test, ANOVA } \\
\text { one-way) }\end{array}$ \\
\hline \multirow{3}{*}{$\begin{array}{l}\text { Before } \\
\text { training }\end{array}$} & $\begin{array}{l}\text { Maintained } \\
\text { self-care }\end{array}$ & 15 & 20 & 10 & 2.86 & \\
& $\begin{array}{l}\text { Managed } \\
\text { self-care }\end{array}$ & 7.6 & 12 & 6 & 2.16 & P VALUE $=0.003$ \\
& Ensured self-care & 8.6 & 11 & 6 & 1.78 & \\
After & Total score & 31.2 & 43 & 22 & 5.76 & \\
training & $\begin{array}{l}\text { Maintained } \\
\text { self-care }\end{array}$ & 23.9 & 32 & 19 & 4.38 & \\
& Managed & 13.7 & 19 & 10 & 2.59 & P VALUE $=0.003$ \\
& self-care & & & & & \\
& Ensured self-care & 15 & 23 & 11 & 3.21 & \\
\hline
\end{tabular}

Table 3. Classification of self-care scoresobtained by heart failure patientsbefore and after training

\begin{tabular}{lllll}
\hline Classification of self-care behavior scores & Low score & Moderate to low score & Moderate to high score & High score \\
\hline Self-care score before training & $90 \%$ & $10 \%$ & $0 \%$ & $0 \%$ \\
Self-care score after training & $0 \%$ & $70 \%$ & $30 \%$ & $0 \%$ \\
\hline
\end{tabular}


Table 4. Comparison of self-care behavior scores before and after training based on demographic variables

\begin{tabular}{|c|c|c|c|c|c|}
\hline Demographic variables & Subcategories & 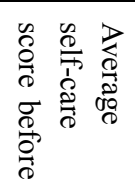 & Tests & 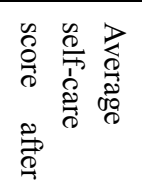 & Tests \\
\hline \multirow[t]{2}{*}{ Gender } & Male & 29 & $\mathrm{~F}=2.050$ & 50.75 & $\mathrm{~F}=0.504$ \\
\hline & Female & 32.66 & $0.169=\mathrm{P}$ value & 53.83 & $0.487=\mathrm{P}$ value \\
\hline \multirow[t]{2}{*}{ Marital status } & Unmarried & 35.5 & $\mathrm{~F}=1.609$ & 50 & $\mathrm{~F}=0.456$ \\
\hline & Married & 29.85 & $0.229=\mathrm{P}$ value & 52.57 & $0.641=P$ value \\
\hline \multirow[t]{2}{*}{ Occupational status } & Unemployed & 33.2 & $\mathrm{~F}=2.612$ & 54.8 & $\mathrm{~F}=1.103$ \\
\hline & Self employed & 29.2 & $0.123=\mathrm{P}$ value & 50.4 & $0.308=P$ value \\
\hline \multirow[t]{3}{*}{ Last degree completed } & Illiterate & 29 & $\mathrm{~F}=2.713$ & 52.25 & $\mathrm{~F}=3.308$ \\
\hline & Diploma & 30.75 & $0.095=\mathrm{P}$ value & 57.25 & $0.061=P$ value \\
\hline & High school & 36.5 & & 44 & \\
\hline
\end{tabular}

\section{Discussion}

According to the findings, most of the research samples had obtained a low score on self-care behaviorbefore training while most of the samples obtainedmoderate to low score after the training. In the study done by Shojai and others (Moraveji et al., 2015) before training most of the research samples had obtained a low and moderate to low score on self-care behaviorbefore training, which isconsistent with theresults of the present study.

Unfortunatelyin performing self-care behaviors, these patientsare facing several impediments such as lack of information, physical limitations, lack of compatibility with multiple and complex therapies, emotional problems and affliction with other chronic diseases. Naturally all these factors greatly affect their self-care behaviors (Riegel \& Carlson, 2002; Stromberg, 2005) and reduce their self-care score. As a result, necessary trainings should be givenon self-care.

The results indicate thatpatients'score on observance ofself-care behaviorincreasedafter the training. This suggests that the research subjects are receptive to training and the training proved successful.

Self-care is a very important concept in chronic diseases, especially heart failure. Its measurement showsa true evaluation of patients'performance and ability in self-care (Moadab et al., 2014).

In the present study, results showed that state of self-care is undesirable in the majority of the centers under study. This follows from thefact that the research environment is a governmental center and most clients are of advanced age, low education and low socioeconomic status, and is consistent with the results of Shjaii and others (Moadab et al., 2014).

In this regard, the results of Heo and others, who identified the factors associated with self-care behaviors in patients with heart failure in the United States, agree with the results of the present studyand show that the average scores of self-care behavior in the centers under study was less than 70, suggesting that the majority of women and men suffering from heart failure do not apply stable self-care behavior (Heo, Moser, Lennie, Riegel, \& Chung, 2008).

Similarly, the results of Jaarsma and others, who compared self-care behaviors in patients with heart failure in 15 countries, showed that self-care behavior in these patients was less than desirable and this situation needs worldwide planning and improvement (Jaarsma et al., 2013).

However, the study by Klimm and others showed that the total score of self-care was high in the centers under study (Peters-Klimm, Freund, Kunz, Laux, Frankenstein, Müller-Tasch, \& Szecsenyi, 2013).

This inconsistency may be due to the use of various tools in evaluation of self-care.

With respect to education, the findings suggest that high school diploma holders, the middle school diploma holders, and finally the illiteraterespectively obtained higher scores before the training. This means that the higher education, the more scores. After the training, however, the illiterate and the middle school diploma holders obtained higher scores and self-care education was more effective in this group compared to the high school 
diploma holders as the study by Moaddab and others suggests.

In addition, people with lower educational level participate to a lesser extent in decision-making, care, and treatment programs and experience disability and more social-psychological distress due to the lack of awareness of the disease, treatment, and self-care. In the present study, a higher percentage of women had a lower educational levelthat can be associated with their weaker self-care condition (Moadab, 2014)

The results indicate that the average scores before and after training were higher than those of men. However, the average score was higher in married subjectsafter training.

In their study on hemodialysis patients, Ismaili and others (2005) showed that the average score of self-efficacy achieved by males washigher than that of females and that the males were more confident of their ability to perform self-care behaviors, whichmight have affected self-care in male patients in this study. On the other hand, probably due to their centrality in doing household chores and housework, women have less opportunity to enhance self-care behaviors (Artinian, Magnan, Sloan, Lange, \& Michigan, 2002).

Nonetheless, the fact is not consistent with the results of the present study. The reasonbehind this difference is that since most samples were of advanced age and did not best receive the training, they obtained lower self-care behavior score.

In this study, married people showedbetter self-care behaviors compared to widowersand widows, but the unmarriedobtained the highest scoreson their self-care behaviors. However, in this study, the unmarriedwere more educated than other groups, which could have affected their knowledge and self-care behaviors. On the other hand, due to fewer family responsibilities compared to married people, the unmarried had more time to perform self-care behaviors (Moadab, 2014).

Rockwell's study suggests that the patients with higher educational levels enjoy better judgment and decision-making capacities regarding their self-care behaviors (Rockwell \& Riegel, 2002), which is consistent the results of the present study.

\section{Conclusion}

Given that self-care behavior in patients suffering from heart failure is of great importance and thatthe patients under the present improved their self-care from a low status to a moderate to low one, it is essential to make intervention efforts to promote self-care behavior and to control the disease, its complications, its relapse, hospitalization, and premature death.To promote self-care behavior and ultimately control heart failure, the application of a training program, designed in the present study, is recommended and emphasized as a model. It should be noted that using health training experts in health centers or media programs as well as the preparation of books and training pamphlets for patients and their familieswillhelp more than ever to promote self-care in patients with heart failure because pre-knowledge on the intended area is the first step in carrying out a project (Shojafard, Nadrian, Baghiani Moghadam, Mazlumi Mahmudabad, Sanati, \& Asgar Shahi, 2009).

\section{Application of Research Findings in Clinical Practice}

The results of the present study help directors and persons in charge of hospitals to provide useful information for further services to its clients in terms of quality and quantity and use them in annual evaluation, resulting finally in more self-care in patients with heart failure.

\section{Acknowledgements}

The present study was approved by the Ilam University of Medical Sciences under code 2/ 94654 dated September 2015. For this purpose, I would like to appreciate Deputy for Research and Technology department of Ilam University of Medical Sciences for the financial support and all the patients who participated in the study.

\section{Competing Interests Statement}

The authors declare that there is no conflict of interests regarding the publication of this paper.

\section{References}

Alizadeh, Z., Ashktorab, T., NikravanMofrad, M., \& Zayeri, F. (2014). Correlation between perceived social support and self-care behaviors among patients with heart failure. JHPM, 3(1), 27-34. [In Persian]

Artinian, N. T., Magnan, M., Sloan, M., Lange, P., \& Michigan, D. (2002). Self care behaviors among patient with heart failure. Heart \& Lung: The Journal of Critical Care, 31(5), 161-72. http://dx.doi.org/10.1067/mhl.2002.123672

Bagheri, H., Yaghmaei, F., Ashktorab, T., \& Zayeri, F. (2015). Evaluation of Social Dignity and its Related Factors 
in Heart Failure Patients. Journal of Knowledge \& Health Shahroud University of Medical Sciences, 10(3), 68-72. [In Persian]

Chattoo, S., \& Atkin, K. M. (2009). Extending specialist palliative care to people with heart failure: Semantic, historical and practical limitations to policy guidelines. Social Science \& Medicine, 69(4), 147-53. http://dx.doi.org/10.1016/j.socscimed.2009.02.025

Gonzalez, B., Luopn, J., Urrutia, A., Altimir, S., \& Coll, R. (2005). Patient education by nurse: What we really do achieve? European Journal of Cardiovascular Nursing, 4(3), 107-11. http://dx.doi.org/10.1016/j.ejcnurse.2005.03.006

Heo, S., Moser, D. K., Lennie, T. A., Riegel, B., \& Chung, M. L. (2008). Gender differences in and factors related to self-care behaviors: A cross-sectional, correlation study of patients with heart failure. International Journal of Nursing Studies, 45(12), 1807-15. http://dx.doi.org/10.1016/j.jnurstu.2008.05.008

Jaarsma, T., Strömberg, A., Ben Gal, T., Cameron, J., Driscoll, A., Duengen, H. D., ... Riegel, B. (2013). Comparison of self-care behaviors of heart failure patients in 15 countries worldwide. Patient Educ Couns, 92(1), 114-120. http://dx.doi.org/10.1016/j.pec.2013.02.017

Johansson, P., Dahlstrom, U., \& Brostrom, A. (2005). Factors and interventions influencing health-related quality of life in patients with heart failure: A review of the literature. European Journal of Cardiovascular Nursing, 5(2), 5-15. http://dx.doi.org/10.1016/j.ejcnurse.2005.04.011

Moadab, F., Ghanbari, A., Salari, A., Kazemnejad, E., SadaghiSabet, M., \& Pariad, E. (2014). Study Status of Self-Care Behaviors and Gender Differences in Patients with Heart Failure. Payavard, 8(3), 220-234. (In Persian)

Moraveji, M., Yaghmaei, F., \& Bagheri, H. (2015). Dignity of heart failure patients referred to Zanjan hospitals. JHPM, 4(4), 75-83. [In Persian]

Morovati, Sh., \& Rouhani Tonekaboni, N. (2009). Social support and self-care behaviors in diabetic patient referring to Yazd diabetes research center. Tabibe Shargh, 9(4), 275-84. [In Persian]

Peters-Klimm, F., Freund, T., Kunz, C., Laux, G., Frankenstein, L., Müller-Tasch, T., \& Szecsenyi, J. (2013). Determinants of heart failure self-care behavior in community-based patients: A cross-sectional study. Eur J CardiovascNurs, 12(2), 167-76. http://dx.doi.org/10.1177/1474515112439964

Riegel, B., \& Carlson, B. (2002). Facilitators and barriers to heart failure self care. Patient Education and Counseling, 46, 287-95. http://dx.doi.org/10.1016/S0738-3991(01)00165-3

Rockwell, J. M., \& Riegel, B. (2002). Predictor of self care in persons with heart failure. Heart \& Lung: The Journal of Critical Care, 30(4), 18-25.

Sandra, B., Clarck, P. C., Quinn, C., Gary, R., \& Kaslow, N. (2008). Family influences on heart failure self-care and outcomes. Journal of Cardiovascular Nursing, 23(3), 258-65. http://dx.doi.org/10.1097/01.JCN.0000305093.20012.b8

Shojafard, J., Nadrian, H., Baghiani Moghadam, M., Mazlumi Mahmudabad, S., Sanati, H., \& AsgarShahi, M. (2009). Effects of an educational program on self-care behaviors and its perceived benefits and barriers in patients with Heart Failure in Tehran. Payavard. 2(4), 43-55. [In Persian]

Stromberg, A. (2005). The crucial role of patient education in heart failure. European Journal of Heart Failure, 12(7), 363-69. http://dx.doi.org/10.1016/j.ejheart.2005.01.002

\section{Copyrights}

Copyright for this article is retained by the author(s), with first publication rights granted to the journal.

This is an open-access article distributed under the terms and conditions of the Creative Commons Attribution license (http://creativecommons.org/licenses/by/4.0/). 